\title{
Ruídos entre nós: escuta em tempos de atendimento remoto
}

\author{
Noises between us: listening in times of remote care
}

\author{
Pâmela Soares Bratkowski' e Renata Isabel Fedrizzi ${ }^{2}$
}

Resumo: A inesperada pandemia de Covid-19 mobilizoua humanidade de forma avassaladora. Diante da inegável necessidade de adaptações e reinvenções, evidenciou-se o aumento dos atendimentos online e telefônicos no intuito de viabilizar o trabalho psicanalítico. Psicólogos, psicanalistas e pacientes precisaram encontrar uma maneira de realizar os atendimentos diante deste novo contexto a fim de que a escuta do inconsciente, que movimenta o nosso ofício, pudesse continuar a ser feita. Para isto, foi necessário refletir sobre a flexibilidade e a ampliação da técnica frente a imposição global do isolamento social. As mudanças trouxeram novos elementos para os atendimentos, mas também mobilizaram antigos conflitos. Neste artigo, objetivou-se problematizar a temática da escuta e seus efeitos no contexto atual por meio de uma revisão narrativa de literatura. A partir de textos clássicos e contemporâneos da psicanálise, dissertamos sobre os ruídos, ou seja, as interferências existentes na comunicação com o paciente nesta modalidade de atendimento.

Palavras-chave: Psicoterapia on-line; Terapia on-line; Clínica psicanalítica.

\begin{abstract}
The unexpected pandemic of Covid-19 mobilized humanity in an overwhelming way. In view of the undeniable need for adaptations and reinventions, there was an increase in online and telephone calls in order to make psychoanalytic work feasible. Psychologists, psychoanalysts and patients needed to find a way to carry out the calls in the face of this new context so that listening to the unconscious, which moves our craft, could continue to be done. For this, it was necessary to reflect on the flexibility and the expansion of the technique in face of (the global imposition of social isolation. The changes brought new elements to the calls, but also mobilized old conflicts. In this article, the objective was to problematize the theme of listening and its effects in the current context through a narrative literature review. Based on classic and contemporary texts from psychoanalysis, we talk about noise, that is, the interferences that exist in communication with the patient in this type of call.
\end{abstract}

Keywords: On-line Psychotherapy; E-Therapy; Psychoanalytic clinic.

\footnotetext{
1 Psicóloga. Diretora científica da SPRGS (Gestão 2020-2022). Psicanalista em formação pela Sigmund Freud Associação Psicanalítica. E-mail: pamelasoaresb@gmail.com

2 Psicóloga. Membro efetivo da SPRGS. Psicanalista em formação pela Sigmund Freud Associação Psicanalítica. E-mail: renataisabelfedrizzi@gmail.com
} 


\section{Introdução}

Você está me escutando bem? Você me ouve? Está aí? Possivelmente estas foram algumas das perguntas mais escutadas neste ano nos atendimentos clínicos. Psicólogos e psicanalistas, assim como outros profissionais, tiveram que adaptar suas atividades para 0 ambiente on-line em decorrência da pandemia de Covid-19 e da necessidade de distanciamento social a fim de conter a disseminação da doença.

Os atendimentos que, em sua maioria, até então aconteciam nos consultórios, passaram a ser realizados por meio de chamadas de vídeo e ligações telefônicas. Essa mudança não ocorreu apenas como uma possibilidade, mas também como uma necessidade para que os espaços de escuta fossem mantidos, principalmente em um momento tão necessário frente à catástrofe e ao desconhecido que vivemos.

As mudanças ocorreram de forma brusca, impossibilitando que esse novo formato de escuta fosse pensado e discutido paulatinamente por psicólogos e psicanalistas, os quais recém estavam começando a pensar no tema. Dessa forma, os questionamentos e indagaçôes foram ocorrendo lado a lado com a adaptação ao atendimento remoto. Foram lives, cursos, reuniões, leituras e releituras que possibilitaram que a escuta continuasse.

Contudo, tais espaç̧os não trouxeram respostas, mas abertura para novas questões, pois, afinal, como acontece a escuta em um momento de pandemia? Existe escuta on-line? Quais são os efeitos nos pacientes? Há atravessamentos na escuta remota? Como possibilitar um espaço de escuta fora do consultório?

Os questionamentos norteadores do presente artigo evidenciam interferências, que optamos por chamar de rúdos, no atendimento remoto. Não qualificamos estes rúdos como positivos ou negativos, mas, sim, como aspectos que apresentam singulares especificidades a serem relativizadas pelo analista ao decidir por trabalhar nesse formato e sugerir essa modalidade ao paciente.

No atendimento remoto, por vezes, a ligação cai, a chamada de vídeo trava, a comunicação falha e outras situações se atravessam na escuta. Esses acontecimentos produzem certos "cortes" na associação livre do paciente e não podem ser negados por parte de quem os escuta. No entanto, também é importante estarmos atentos e pensarmos no que está por trás dos efeitos desses acontecimentos reais que se impõem. A atenção flutuante e a percepção daquilo que está para além do que é dito não mudam nesse contexto, apenas não estão mais no antigo enquadre com o qual estávamos acostumados há tantos anos.

Nesse sentido, faz-se necessário estudarmos tais fenômenos que se apresentam na escuta psicanalítica atual à luz de conceitos já conhecidos por nós. Isso porque, a refletirmos sobre os fenômenos que se apresentam nesse formato de atendimento fundamentado na teoria clássica, podemos pensar na ampliação da técnica analííica.

\section{Metodologia}

Este artigo foi escrito por duas sócias da Sociedade de Psicologia do Rio Grande do Sul que passaram a se questionar sobre as mudanças no setting terapêutico provenientes do distanciamento social em decorrência da Covid-19. 0 formato escolhido para o estudo do tema foi o de revisão narrativa da literatura por meio de textos clássicos de Freud e de autores contemporâneos que dissertam sobre a clínica psicanalítica.
Para a construção do artigo, optou-se por dividi-lo nos eixos "Você me ouve?", "É possível um divã virtual?" e "Que ruídos são estes?". Em cada um deles, foram utilizados conceitos psicanalíticos com o objetivo de pensarmos sobre os ruídos que existem na comunicação com o paciente na modalidade de atendimento virtual.

\section{Você me ouve?}

Nos atendimentos remotos, quando o paciente nos questiona se estamos 0 escutando, ele pode estar de fato se referindo à instabilidade da ligação e ter dúvida se a chamada está ativa. É necessário entendermos que existem interferências na conexão e na rede que podem comprometer a escuta do analista e do analisando. No entanto, não podemos perder de vista o questionamento, a fim de pensar o que pode estar para além do que é manifestado pelo paciente.

Se refletirmos sobre 0 apontamento de Freud, em Recomendaçōes aos médicos que exercem a psicanálise (1996-1912b) - de que, se prestarmos demasiada atenção ou fixarmos em um ponto específico do que nos é dito, corremos o risco de seguir nossas próprias inclinações ou não escutarmos algum material - podemos perceber que o mesmo cuidado deve ser tomado em relaçãa a as ruídos no atendimento remoto. Precisamos escutar a pergunta "você me ouve?" para além do objetivo de saber se estamos em linha e escutando a voz do paciente.

Para Freud (1996-1912b), devemos nos colocar na posição de utilizar tudo o que nos é comunicado para os propósitos da interpretação e do reconhecimento do inconsciente oculto. Ao esquecermos essa recomendação, poderemos não escutar que o paciente está com dúvidas se podemos entendê-lo ou então de que se trata de uma resistência, por exemplo. A mesma pergunta poderia facilmente ser feita pelos pacientes no consultório e de fato o é, pois écomum os pacientes imaginarem que estamos pensando em outras coisas ou que não conseguiremos compreender a sua dor. Além disso, essa pergunta também pode ser empregada por parte do paciente com o objetivo de interromper uma associação de ideias.

No capítulo VII de A interpretação dos sonhos, Freud (1996-1900) refere que os traços dos sonhos que parecem mais insignificantes são exatamente os mais imprescindíveis para a interpretação do material apresentado e necessários para a continuidade do processo. Assim como na escuta de um sonho, também precisamos nos atentar a cada detalhe, por mais irrelevante que este pareça nos atendimentos. Nos atendimentos remotos, uma pergunta sobre a conexão da internet pode nos revelar bem mais do que parece.

Freud (1996-1912b) refere que o psicanalista deve se"colocar na posição de fazer uso de tudo o que lhe é dito para fins de interpretação e identificar 0 material inconsciente oculto, sem substituir sua própria censura pela seleção de que o paciente abriu mão" (p. 129). No mesmo texto, Freud pontua que as questões não resolvidas por parte do analista podem se configurar como pontos cegos. Com base nas afirmações do pai da psicanálise, precisamos estar atentos para não misturar as nossas próprias vivências com as daquele que escutamos, ou seja, precisamos entender o sentido para o paciente de tudo que nos é dito. Macedo e Falcão (2005) referem que Freud inaugurou tempos de escuta que ressaltam a singularidade de sentidos da palavra enunciada pelo paciente.

Apesar de, atualmente, por exemplo, estarmos em um momento no 
qual vivemos coisas parecidas com os nossos pacientes, devemos nos atentar para não cair na tentação de acharmos que sabemos do que o paciente está falando e tratar como óbvia a pergunta "você me ouve". Freud (1996-1912b) já nos advertiu sobre a importância de não confidencializarmos aos pacientes sobre as nossas próprias questões e nem nos colocarmos em condição de igualdade a eles, pois isso nos afasta do tratamento psicanalítico e pouco ajuda no método de trabalho.

Freud (1996-1912b) também refere que um psicanalista que decide falar para o paciente sobre a sua vida com o propósito de aproximá-lo pode inicialmente conseguir que coisas Ihe sejam ditas. No entanto, em pouco tempo, é possível perceber que este método não é eficaz e pode, inclusive, dificultar 0 processo e a continuidade do tratamento. Desse modo, dizer ao paciente que também temos problemas de conexão, que nosso pacote de internet não é bom ou outras coisas nesse sentido, pouco ajudará no processo terapêutico.

Nesse mesmo sentido, cabe ressaltar que, apesar de estarmos vivenciando uma situação traumática e perturbadora para todos, conflitos, gozos e fantasias singulares há muito tempo soterrados podem ser mobilizados pela crise atual (Capoulade \& Pereira, 2020). A escuta em psicanálise leva em consideração a singularidade de cada sujeito e tem um caráter único no que se refere à necessidade de cada um dos pacientes. Não há uma fórmula ou receita, mas, sim, uma possibilidade de oferecer uma escuta que vai para além das próprias imagens e ideias que a pessoa tem sobre si mesmo; isto é o que inaugura a arte de escutar como uma forma de transformação e de cura (Dunker \& Thebas, 2019).

Segundo Macedo e Falcão (2005), Freud "inaugura a singularidade de uma situação de comunicação entre paciente e analista. Um chega com palavras que demandam um desejo de ser compreendido em sua dor, o outro escuta as palavras por ver nestas as vias de acesso ao desconhecido que habita o paciente" (p. 65). As autoras também sinalizam que as palavras ditas pelo paciente nem sempre são claras, mas, sim, enigmáticas e, por isso, necessitam de uma escuta que possa as compreender em sua singularidade.

\section{É possível um divã virtual?}

Repensar a psicanálise se tornou necessário no ano de 2020. Aliás, questões que já estavam se apresentando e necessitando de espaço para serem pensadas rapidamente entraram em cena com a disseminação da Covid-19e a adaptação às mudanças impostas pela doença. Isso porque não foi apenas nesse momento que surgiram os atendimentos remotos e a necessidade de ampliação da técnica.

A pandemia levou os psicólogos e psicanalistas a se desacomodar e repensar sobre suas práticas a fim de que a psicanálise seguisse vigente em tempos tão controversos. Os divãs foram substituídos por sofás e camas, assim como os consultórios, pelas casas dos pacientes. Com isso, muitas dúvidas surgiram, por exemplo, como seria possível viabilizar um tratamento sem que o psicanalista pudesse assegurar um espaço de escuta privado e sem interferências?

Nas sessões presenciais, a partir do uso do divã, possibilita-se o menor número de interferências externas e visuais para que o paciente possa"sonhar acordado". Essa ferramenta de trabalho contribuiu para o aprimoramento da técnica analítica e a construção do modelo clássico de psicanálise. Sendo assim, como ficam os atendimentos quando não há mais os divãs, familiares batem na porta do ambiente em que o paciente está ou, até mesmo, adentram o espaço?
Não podemos esquecer das inúmeras vezes que os telefones dos pacientes tocam com outras chamadas ou eles recebem mensagens e notificações de aplicativos. Todas essas interferências não podem mais ser controladas pelos psicólogos e psicanalistas, a preservação de um espaço de escuta passa a ser compartilhado entre psicanalista e paciente, o que rompe com antigos moldes de escuta.

Em relação às diferenças nas modalidades de escuta, Coppus (2020) aponta para possíveis perdas que existem no atendimento remoto como 0 tempo de espera na sala de recepção e o caminho até o consultório. Para a autora, esses momentos são frutíferos, pois introduzem um intervalo que diverge do tempo comum e marca o início de um tempo de fala. No entanto, a autora refere que, em contrapartida, al guns pacientes demonstraram maior facilidade para falar, maior produção de sonhos e uma diminuição de faltas e silêncios.

Em o Início do tratamento, Freud (1996-1913) menciona que"a extraordinária diversidade das constelações psíquicas envolvidas, a plasticidade de todos os processos mentais e a riqueza de fatores determinantes opõem-se a qualquer mecanização da técnica" (p. 139). Ele sinaliza que os procedimentos considerados corretos na psicanálise podem fracassar em al guns casos, assim como aqueles entendidos como errados podem contribuir com o processo. Dessa forma, é necessário que o psicanalista possa analisar a singularidade de cada paciente e de cada situação, a fim de possibilitar uma escuta individual e contextualizada em seu tempo.

Gondar (2020) refere que todos os psicanalistas, de certa forma, tiveram neste ano que "admitir algo que Ferenczi sempre nos convocou a enxergar: quem recebemos em tratamento não é apenas um sujeito, mas um sujeito e sua circunstância; se não a levamos em conta, não poderemos tratá-I0"(p. 38). A psicanalista citada questiona o posicionamento daqueles que não enxergam 0 atendimento remoto como uma possibilidade e como sendo uma forma de fazer psicanálise. Além disso, ela menciona que, ao resistirmos a este novo formato de atendimento, podemos" "resistir a entrar num novo modo de sentir e de perceber os pacientes e, consequentemente, vamos resistir ao encontro e à situação clínica" (Gondar, 2020, p. 41).

No mesmo texto, Jô Gondar cita o pensadorWalter Benjamin para referir que a percepção é algo histórico e cultural. Assim, com o passar dos anos, ocorrem mudanças em nossa sociedade, e as velhas percepções entram em choque com a realidade que se apresenta quando a olhamos "com antigos olhos". Esse apontamento não se trata de invalidar o que até então foi construído e teorizado, mas, sim, de poder ampliar o que se conhece e contextualizar ao tempo que vivemos.

Nesse sentido, a autora aponta que ficamos muito cansados durante os atendimentos ou não conseguimos escutar os pacientes quando ficamos capturados a uma antiga percepção ou uma única forma de presença que seria nos consultórios (Gondar, 2020). Ela diz que"nas análises on-line não se perde a presença, e sim um certo modo de presença" (Gondar, 2020, p. 41). A partir desse novo modo, precisamos repensar a nossa técnica e fazer trabalhar a psicanálise, pois nos deparamos "com um não saber fazer que transigia invenções, arranjos, compromissos e mesmo rupturas" (Connus, 2020, p. 131).

Por meio de uma escuta cuidadosa e ética, a atenção livre do analista continua ocorrendo no ambiente remoto, e o paciente pode seguir associando livremente, comunicando tudo o que Ihe ocorre em busca da cura. Freud (1996-1913), em O início do tratamento, diz que o paciente deve ser orientado a comunicar tudo o que the ocorre por mais que the pareça desagradável e 
irrelevante. Éa partir dessa comunicação do paciente que se abre espaço para o desvelamento da palavra e do desconhecido que habita o sujeito (Macedo \& Falcão, 2005).

A associação livreéa regra fundamental da psicanálise. Ela foi descoberta após uma série de mudanças e da evolução da técnica, que permitiram a Freud se dar conta que não deveria interromper o fluxo de pensamentos de seus pacientes, mas, sim, deixá-los falar livremente o que Ihes ocorresse na mente. Isso porque ele percebeu que existia uma instância psíquica oculta, capaz de guiar e determinar a direção do pensamento, confirmando que as temáticas que surgiam a partir da associação livre tinham relação e sentido umas com as outras (Fischer, 2012).

De acordo com Laplanche e Pontalis (2001), 0 analisando é convocado a falar sobre o pensa e sente sem nada escolher ou omitir. Ainda segundo os autores, tal técnica consiste em educar o paciente a renunciar a qualquer atitude crítica e, então, a partir do que é revelado, pode-se fazer uma relação com o material recalcado do paciente. No atendimento remoto, o paciente deve não apenas renunciar à crítica e à moralidade, como também a todos os ruídos que possam surgir durante 0 atendimento.

Além das dúvidas em relação à efetividade da escuta nos atendimentos remotos, Gondar (2020), assim como outros psicanalistas, também questiona o silêncio nesse formato de atendimento. Isso se deve ao fato de que, por vezes, nos consultórios, os pacientes ficam vários minutos em silêncio. Porém, no atendimento remoto, muitas vezes, o silêncio é interrompido por um questionamento, como "você está aí?" e"achei que a ligação havia caído".

Os questionamentos citados acima podem de fato ser em relação a uma dúvida por parte do paciente se estamos conectados ou em linha. No entanto, também pode ser uma forma de interromper o silêncio e as reverberações que ocorrem no mundo interno do paciente durante os atendimentos.

\section{Que ruídos são estes?}

Nos atendimentos remotos, sejam eles on-line ou por telefone, deparamo-nos com ruídos que irrompem as sessões. Estes podem se apresentar como interferências na rede ou, ainda, fazer parte da comunicação inconsciente do sujeito que busca tratamento pelo desejo de ser escutado. Sendo assim, poderíamos pensar que o não silenciamento de ligações que interrompem 0 atendimento ou 0 questionamento por parte do paciente se estamos 0 escutando é uma manifestação de resistência?

Ao nos questionarmos sobre as situações que ocorrem durante os atendimentos, abrimos a possibilidade de escutar o que está sendo posto em ato e ajudar a transformar em palavra. Isso não quer dizer que toda e qualquer situação que se atravessa no tratamento seja uma resistência, pois muitas situações que ocorrem na vida do paciente são alheias às suas intenções. No entanto, conforme afirma Freud (1996-1900, p. 544), "a resistência se evidencia inequivocamente na presteza com que o paciente aceita esse tipo de ocorrência ou no uso exagerado que dela faz".

Freud menciona, em 0 início do tratamento (1996-1913), que o paciente procura meios para romper com a regra de falar tudo o que lhe vem à mente. No atendimento remoto, o paciente pode encontrar na falha de conexão da internet ou no sinal da ligação uma maneira de ocultar materiais preciosos.

Ferenczi (1928) menciona que 0 analista deve estar atento aos sinais que revelam incredulidade ou recusa do paciente por meio do contexto associativo e comunicá-los ao paciente, pois a resistência não perde nenhuma oportunidade. 0 analista deve estar atento, mas não afrontar o paciente, a fim de não prolongar o período de resistência e deixar que aos poucos o paciente possa enfrentar esse período resistencial que se apresenta.

A resistência é um conceito fundamental para a psicanálise e encontra-se em inúmeros textos da obra freudiana, atravessando todo o processo analítico. Por meio de uma síntese das definições, o conceito de resistência na psicanálise, segundo Laplanche e Pontalis (2001), caracteriza-se por"tudo o que, nos atos e palavras do analisando, se opõe ao acesso deste ao seu inconsciente" (p. 458). Segundo Roudinesco e Plon (1998), o termo é definido como "0 conjunto das reações de um analisando cujas manifestações, no contexto do tratamento, criam obstáculos ao desenrolar da análise" (p. 659).

No entanto, em Resistência e Repressão (Freud, 1996-1917) é possível entender que o fenômeno da resistência também é de grande utilidade ao tratamento. Com base nisso, constata-se a amplitude da temática e a necessidade de nos ocuparmos em compreendê-la mais intimamente para refletirmos suas manifestações presentes no tratamento.

Násio (1999), em seu livro Como trabalha um psicanalista?, afirma que o desejo recalcado é inacessível à consciência em razão das resistências de contradição ao Eu. 0 Eu resiste em vivenciar o desprazer que emerge a partir do recalcado inconsciente e o que isso representa. Sendo assim, a resistência é sempre contra a dor e ao sofrimento. Dessa forma, poderíamos pensar que no atendimento remoto fica mais fácil de afastar o material reprimido já que existem interferências na associação livre?

0 conceito de recalcamento na teoria psicanalítica é definido como a "operação pela qual o sujeito procura repelir ou manter no inconsciente as representações (pensamentos, imagens, recordações) ligadas a uma pulsão" (Laplanche \& Pontalis, 2001, p. 430). Sendo o funcionamento do aparelho psíquico baseado no princípio do prazer, que visa satisfação pulsional, ao suceder 0 acúmulo de energia que não pode obter tal satisfação, acaba por ser percebido como desprazer, produzindo, assim, o recalcamento.

A resistência tem a função de evitar que estas pulsões se tornem conscientes, o que aponta que a dificuldade de acesso provém da importância do elemento que está sendo mantido oculto. Ao fazer circular tais intensidades pulsionais, o sujeito se encontra compelido a se ver com a necessidade de acionar recursos defensivos frente à angústia. Assim, o recalcamento denuncia a ação de operações defensivas e a força ativa do que ameaça o equilíbrio psíquico (Macedo, 2016).

Em A dinâmica da transferência, Freud (1996-1912a) define que o processo analítico opera por meio da transferência, podendo se tornar a resistência mais poderosa ao tratamento. A intensidade e a persistência da transferência constituem o efeito gerado por esse fenômeno, que leva em consideração a resistência, explicitando a ideia da relação existente entre o que é transferido e as recalcadas demandas infantis insatisfeitas.

Com base neste percorrido, podemos perceber que os ruídos na comunicação dos atendimentos remotos podem se referir a fatores externos e independentes do paciente, mas também podem ter origem interna. Uma escuta atenta e profunda, que rompa com a lógica consciente, possibilita 0 desvelamento das palavras e do silêncio do paciente.

Por vezes "um charuto é apenas um charuto". No entanto, o inconsciente busca formas de se comunicar. Por esse motivo, precisamos estar atentos e 
entender o sentido singular de cada situação. Caso, por exemplo, alguém entre no ambiente no qual o paciente está realizando sua sessão, podemos por um lado pensar que esta foi uma situação alheia a ele. Todavia, também podemos analisar os motivos pelos quais o paciente não comunicou que não poderia ser interrompido ou não trancou a porta.

Outra situação que podemos pensar é o fato de que, frente à impossibilidade de os atendimentos continuarem nos consultórios devido à pandemia, alguns pacientes encontraram formas de realizar seus atendimentos de forma remota e outros pontuaram sobre uma impossibilidade. Éverdade que algumas pessoas não têm um ambiente físico tão adequado, no entanto, percebemos que outras com situações muito semelhantes criaram um espaço possível dentro de suas próprias casas.

\section{Considerações finais}

A partir deste estudo, no qual buscamos, por meio de perguntas, compreender como se dão os atendimentos no ambiente remoto e qual os seus efeitos no tratamento, pudemos observar que, apesar de existirem ruídos na comunicação, o espaço de escuta pode ser garantido. É possível estabelecer uma condição que viabilize as manifestações do inconsciente, visto que a distância é apenas física e a presença está preservada.

Por meio desse novo modo de presença, os processos que envolvem os atendimentos, tais como a transferência e a resistência, permanecem ocorrendo, mesmo que de outras formas. Sendo assim, os psicólogos e psicanalistas devem ampliar suas escutas e acompanhar as mudanças que ocorrem no contexto no qual estão inseridos, a fim de dar espaço para que a palavra do paciente seja escutada independentemente de um espaço físico.

Pensar na ampliação da técnica e nas formas de exercer a escuta não significa invalidar as questões teóricas e ligadas ao método da psicanálise. Pelo contrário, visa retomar os conceitos e trabalhá-los profundamente com o objetivo de oferecer uma escuta ética e cuidadosa que leve em conta a singularidade do paciente e a sua circunstância. 0 próprio Freud manifestou ter receio de que as regras que norteiam o tratamento se tornassem rígidas.

A pandemia e o distanciamento social, que provocaram tantas incertezas e desamparo frente ao desconhecido, também nos permitiram pensar como a escuta pode acontecer para além dos consultórios e divãs. Apesar de ainda serem necessários debates e estudos sobre o atendimento remoto e seus ruídos na escuta, pudemos concluir que o que possibilita o processo e a cura não são os recursos físicos, mas, sim, a capacidade interna dos psicólogos e psicanalistas.

\section{Referências}

Capoulade, F., \& Pereira, M. E. C. (2020). Desafios colocados para a clínica psicanalítica (e seu futuro) no contexto da pandemia de CoVID-19: reflexões a partir de uma experiência clínica. Revista latino-americana de psicopatologia fundamental, 23(3), 534-548. doi: 10.1590/1415-4714.2020v2 $3 n 3 p 534.6$

Coppus, A. N. S. (2020). Você vai voltar ao consultório? Psicanálise e atendimento on-line. Revista aSEPHallus de Orientação Lacaniana, 15(29), 129139. Recuperado de http://www.isepol.com/asephallus/numero_29/ pdf/09\%20-\%20ALINNE\%20NOGUEIRA.pdf
Dunker, C., \& Thebas, C. (2019). O palhaço e o psicanalista: como escutar os outros pode transformar vidas. São Paulo: Planeta do Brasil.

Ferenczi, S. (2011). Elasticidade da técnica. In S. Ferenzi, Obras completas psicanálise IV (pp. 29-42). São Paulo: Martins Fontes. (Obra original publicada em 1928).

Fischer, V. M. (2012). Passagem do método catártico à associação livre - A origem da psicanálise e a descoberta da realidade psíquica. InV. M. Fischer, Apontamentos psicanalíticos: textos teórico-clínicos e de psicanálise aplicada (pp. 13-17). São Paulo: Zagodoni.

Freud, S. (1996). A interpretação dos sonhos. In S. Freud, Edição Standard das Obras Psicológicas Completas de Sigmund Freud (vol. 5, pp. 539-647). Rio de Janeiro: Imago. (Obra original publicada em 1900).

Freud, S. (1996b). A dinâmica da transferência. In S. Freud, Edição Standard das Obras Psicológicas Completas de Sigmund Freud (vol. 12, pp. 109-119). Rio de Janeiro: Imago. (Obra original publicada em 1912b).

Freud, S. (1996). Recomendações aos médicos que exercem a psicanálise. In S. Freud, Edição Standard Brasileira das Obras Psicológicas Completas de Sigmund Freud (vol. 12, pp. 123-133). Rio de Janeiro: Imago. (Obra original publicada em 1912a).

Freud, S. (1996). Resistência e Repressão. Conferência XIX. Conferências Introdutórias sobre Psicanálise. In S. Freud, Edição Standard das Obras Psicológicas Completas de Sigmund Freud (vol. 16, pp. 293-308). Rio de Janeiro: Imago. (Obra original publicada em 1917).

Freud, S. (1996). Sobre o início do tratamento. In S. Freud, Edição Standard Brasileira das Obras Psicológicas Completas de Sigmund Freud (vol. 12, pp. 137-161). Rio de Janeiro: Imago. (Obra original publicada em 1913).

Gondar, J. (2020). Psicanálise on-line e elasticidade da técnica. Cadernos de Psicanálise (PRJ, 42(42), 37-45. Recuperado de http://www.cprj.com.br/ ojs_cprj/index.php/cprj/article/view/201

Laplanche, J., \& Pontalis, J. (2001). Vocabulário da Psicanálise (4a. ed.) São Paulo: Martins Fontes.

Macedo, M. K. (2016). Transferência: uma esperada visita inesperada. In M. K. M. Macedo (org.), Neurose: leituras psicanalíticas. (4a. ed., pp.217-238.) Porto Alegre: EDIPUCRS.

Macedo, M. K., \& Falcão, C. N. de B. (2005). A escuta na psicanálise e a psicanálise da escuta. Psychê, 9(15), 65-76. Recuperado de https://pesquisa. bvsalud.org/portal/resource/pt/lil-416110

Nasio, J.-D. (1999). Como trabalha um psicanalista? (L. Magalhães, trad. M. A. C. Jorge. revisão técnica) Rio de Janeiro: Jorge Zahar.

Roudinesco, E., \& Plon, M. (1998). Dicionário da Psicanálise. Rio de Janeiro: Zahar. 